\title{
Post-Partum Depression at the Regional Special Hospital of South Sulawesi Province
}

\author{
Rahmiyani Saad ${ }^{1}$, Leli $^{1}$ \\ Corresponding Email: rahmiyanisaad14@gmail.com \\ ${ }^{1}$ Cokroaminoto University of Makassar, Indonesia \\ Received: January 15, 2022 \\ Received in Revised: February 14, 2022 \\ Accepted: February 20, 2022
}

\begin{abstract}
Pregnancy and give birth period is period of life that full of stress potential. Women in pregnancy period and post partum period, incline feels high stress exactly because of having physical condition limitedness that health workers her to do activity and having adaption process become a mother. This period have potential post partum depression. The aims of to do this research is qualitative method with analyze descriptive with collecting data primer technique by independent interview. the research is showed that long labor, parity, mother disease history, husband support, labor with action having potential feels post partum depression. The expect of post partum mother to do communication for all of problems of others that want to express. To talk about worry that happened have sincere attitude to accept activity and new role after labor flexible to learn be calm and consultancy to doctor or professional person in order to minimalize risk factor in order to post partum depression can be involved.
\end{abstract}

Keywords: Post Partum Depression, Long Labor, Husband Support, Labor Compication

\section{Introduction}

Pregnancy and childbirth are periods of life full of potential stress. A woman in the period of pregnancy and the postpartum period tends to experience considerable stress due to limited physical conditions that make her have to limit activities and undergo the process of adaptation to become a mother. This period has the potential for postpartum depression.

Stress is a condition caused by the interaction between the individual and the environment that gives rise to the perception of the distance between the demands that come from the situation and the resources of the biological, psychological and social systems of a person in the form of physical and mental tension that can reduce productivity, pain, and mental disorders (Hairiyah 2011). According to Sarfino (1990) in Hairiyah (2011) sources of stress can change, in line with human development but stress conditions can also occur at any time throughout life, the source of stress is within the individual, family, community and public.

This stressful event can occur in every individual, especially women who are experiencing pregnancy. This stress can develop into psychosis which causes serious disturbances to the pregnancy process in the form of the production of chemicals in the form of catecolamine which through HPA access and causes contractions in the uterus that lead to premature birth to infant death. This can be one of the risks of postpartum depression.

Post-partum depression according to psychiatrists in 1860 was defined as a change shortly after giving birth According to Chaplin (2001) postpartum depression is a moody state experienced by a woman after giving birth, while according to Anindyajati et al. (2017) Post-partum depression (DPP) is a depression found in women after giving birth that occurs within a period of 4 (four) weeks. This can last up to several months or even years if not addressed 
WHO (1990) found that depression causes the 4th largest social burden in the world and is predicted to reach more than 300 million people in the next two decades. By 2025 depression will be the second largest health problem in the world after cardiovascular disease. According to Banerjee et al. (2017) Structural and functional diversity of nonapeptide hormones from an evolutionary perspective: a review. General and Comparative Endocrinology, 241, 4-23 . (2010) if depression is not handled properly it will develop into post-partum psychosis with a prevalence of $0.1-0.2 \%$.

In Western countries, postpartum depression is experienced by approximately $15-20 \%$ of women who give birth both for the first time and after childbirth, in Malaysia, mothers experience postpartum depression as much as 3.9\%. In Indonesia alone, the Aceh Provincial BKKBN (2012) found 7 out of 10 mothers who gave birth to postpartum depression with symptoms of no appetite and difficulty sleeping. Yogyakarta and Surabaya found the incidence of postpartum depression was $15-20 \%$. Jakarta found that the incidence of postpartum depression was $11-30 \%$ of mothers who experienced postpartum depression

It is important to understand postpartum depression because postpartum depression has the potential to cause the death of the baby and the mother. Anindyajati et al. (2017) explains the causes of postpartum depression in Indonesia in particular, namely, husband's support (from husband or family), condition or quality of the baby (including problems with pregnancy and childbirth), readiness to give birth to a baby and become a mother, labor complications (parity), mode of delivery, history of infectious diseases, complications of labor and duration of delivery) history of previous depression or other emotional problems, hormonal factors and cultural factors

Kruckman (2011) explained that the factors that cause postpartum depression are biological factors due to the hormones estrogen, progesterone and prolactin optimal maternal age for infant care which involves mental readiness to become a mother, primiparous status, education related to social pressure, and role conflict, length of labor. and medical interventions during labour, as well as social support factors. The above causal factors are supported research found a significant relationship between satisfaction in marriage and postpartum depression, women who are not depressed during pregnancy can experience postpartum depression if they do not experience satisfaction in their marriage, on the other hand, women who are depressed during pregnancy, can improve after childbirth when experiencing satisfaction in marriage.

Anindyajati et al. (2017) found that readiness to become a mother also affects the occurrence of postpartum depression. Riani et al. (2013) who found there was a significant relationship between family support, readiness to care for babies with economic status, and the level of postpartum depression.

Depression is characterized by disturbances in psychological conditions that affect the emotional process and way of thinking of a person, a drastically decreased mood (mood) and a reluctance to carry out activities that can affect thoughts, behavior, feelings and comfort. This depression can happen to anyone, including mothers after giving birth

Post-partum depressed mothers are also not enthusiastic about breastfeeding their babies so that the growth and development of their babies are not like babies whose mothers are healthy so that it has an impact on the delay in breastfeeding mothers to their babies due to anxiety, unsupportive moods after giving birth, mental and emotional conditions of mothers in particular. in early birth.

Breastfeeding is very important for babies because giving immunity reduces the risk of intestinal infections, intelligence, brain, and preventing allergies. baby's body fights disease. 
In addition, infants with postpartum depression mothers experience poor development which results in behavioral orientation disorders, verbal development, and delays in scholastic development. This is because depressed mothers are less sensitive to pay attention to their babies which correlate to the psychological relationship between mother and child so that in their development children born to mothers with postpartum depression experience cognitive, behavioral and interpersonal disorders. A more severe condition where mothers with postpartum psychosis are at risk of killing their babies and can easily commit suicide due to the level of postpartum depression.

\section{Methods}

This research is a qualitative research that is a research approach that is directed to collect data, take meaning, gain understanding from the case. The research methods are in-depth interviews, documentation and observation. Instruments in the study are divided into 3 (three), namely; (1) Interview guide, used to dig up information towards the aspects under study in accordance with the objectives. The interview guide used for informants has been tested with other informants. After the trial, there were several questions that developed, namely the addition of questions regarding a more in-depth explanation of postpartum depression. (2) This recording device is used to facilitate documenting the data obtained by using a tape recorder. The recording process has been previously approved and allowed by the informant, (3) Sheets for recording the results of the interview, namely field notes containing answers from the informants which function as documentation of the results of interviews in the field apart from voice recordings. This note also functions as a control question and records new questions according to the development of new findings during the interview.

In this study, the informants included three types, namely: (1), regular or primary informants, namely post-partum mothers who had a history of postpartum depression. (2) Partum. (3) Supporting informants, namely husband/family, friends or colleagues from the mother with a history of post-partum depression, 1 person each.

\section{Results and Discussion}

Table 1. Characteristics of mothers who have experienced Post-Partum Depression at the Regional Special Hospital of South Sulawesi Province

\begin{tabular}{|c|c|c|c|c|l|}
\hline No. & $\begin{array}{c}\text { Initials } \\
\text { Informant }\end{array}$ & $\begin{array}{c}\text { Age } \\
\text { (Year) }\end{array}$ & $\begin{array}{c}\text { Long } \\
\text { depression / } \\
\text { year of events }\end{array}$ & The last education & $\begin{array}{c}\text { Informant's } \\
\text { Job }\end{array}$ \\
\hline 1 & Mrs" A" & 37 & 8 Weeks / 2010 & Junior School & House Wife \\
\hline 2 & Mrs"R" & 42 & 4 Weeks / 2008 & Junior School & House Wife \\
\hline 3 & Mrs"S" & 46 & 3 Weeks / 2013 & Elementary School & House Wife \\
\hline 4 & Mrs"k" & 39 & 6 Weeks / 2006 & Junior School & House Wife \\
\hline 5 & Mrs" D" & 35 & 5 Weeks / 2009 & Elementary School & House Wife \\
\hline
\end{tabular}

Source: Secondary Data rskd sul-sel province

Table 2. Support Informant for Mothers who Have Experienced Post-Partum Depression

\begin{tabular}{|c|c|c|c|c|}
\hline No & Initials Informant & Age & The Last Education & Work \\
\hline 1 & Mr. "P" & 39 & Junior School & Farmer \\
\hline 2 & Mr. "S" & 45 & Elementary School & Laborer \\
\hline 3 & Mr" T" & 42 & Elementary School & Farmer \\
\hline 4 & Mrs" G" & 45 & Junior School & Private Worker \\
\hline 5 & Mr. R" & 37 & Elementary School & Farmer \\
\hline
\end{tabular}


Table 3. key informant for mothers who have experienced post partum depression

\begin{tabular}{|c|c|c|c|c|}
\hline No. & Initials of informant & Age & The last education & Work \\
\hline 1. & Ns & 45 Yrs & S1 & Midwife/nurse \\
\hline
\end{tabular}

Table 1 shows the number of mothers who have experienced postpartum depression as many as 5 people. With an Age Range of 30-40 Years. With the longest suffering about 2 months and the shortest suffering 3 weeks. And the highest education level is SMP $3(60 \%)$ and the lowest education level is SD as much as $2(40 \%)$. And most of the work backgrounds are IRT, which is $5(100 \%)$.

Based on the characteristics of mothers with a history of postpartum depression, namely mothers aged 30-40 years. And the average level of junior high school education and household work. Notoatmodjo (2012) suggests that a lack of education will hinder the development of a person's attitude towards newly recognized values. Meanwhile, Education is the learning of knowledge, skills, and habits of a group of people that are transferred from one generation to the next through teaching, training, or research. Education often takes place under the guidance of others, but it is also possible to be self-taught.

Any experience that has a formative effect on the way people think, feel, or act can be considered educational. Education, mothers who have higher education who work in the formal sector have better access to information about health, are more active in determining their nature and are more independent in taking care actions. The low level of maternal education has an impact on the low knowledge of mothers to obtain health services, the lower the knowledge of mothers, the less desire to use health services (Rukmini, 2005).

Mothers who experience postpartum depression are more experienced at the age of 30-40 years. And this is largely due to the various complications of pregnancy and childbirth experienced by the mother. Age is the age of an individual starting from the time he was born until his birthday. The more old enough, the maturity level of a person and a person's strength will be more mature in thinking (Nursalam et al., 2010).

The age of 20-35 years is considered ideal for pregnancy and childbirth, in this age range the woman's physical condition is in excellent condition. The uterus is able to provide maximum protection or conditions for pregnancy and is generally mentally prepared.

\section{Information about the mother's experience with a history of Post Partum Depression.}

Postpartum depression is a moody condition that is found in a woman after giving birth and occurs within 4 weeks. This can last for several months or even years if not treated (Sari, 2020). Post partum depression is mental stress after giving birth, a mother will feel really inadequate, crushed by the burden of responsibility for the baby and family, unable to do anything to get rid of that feeling.

Pathophysiology During pregnancy, levels of estrogen (estradiol, estriol and estrone) and progesterone increase due to the placenta producing these hormones, as a result of the birth of the placenta during labor, levels of estrogen and progesterone decrease sharply, reaching levels before pregnancy on the fifth day, levels of beta -endorphins, human cryonic gonadotropin (HCG) and cortisol which increase during pregnancy and reach maximum levels near term also decrease during delivery.

High estrogen levels during pregnancy stimulate the production of thyroid hormone binding globulin, increasing T3 (triiodothyronine) and T4 (thyroxime), so that levels of free T3 and T4 decrease. As a consequence, thyroid stimulating hormone (TSH) increases to compensate for low levels of free thyroid hormone, so free T3 and T4 levels remain normal. With decreased 
levels of thyroid hormone binding globulin after delivery, total levels of T3 and T4 decrease, while free T3 and T4 are relatively constant (Yim et al, 2009' Bloch et al, 2006) Estradiol and estriol are active forms of estrogen formed by the placenta, and bind during pregnancy 100 out of 1000 times. As a result of the synthesis of ektradiol derived from the metabolic activity of the fetus, the concentration during pregnancy is very high. Based on animal experiments, strengthening the function of neurotransmitters by increasing the synthesis and reducing the breakdown of serotonin, so theoretically the decrease in estradiol levels due to childbirth plays a role in causing postpartum depression.

WHO found that depression causes the 4th largest social burden in the world and is predicted to reach more than 300 million people in the next two decades. By 2025 depression will occupy the second largest health problem in the world after cardiovascular disease. According to Banerjee et al. (2017) if depression is not handled properly it will develop into post partum psychosis with a prevalence of 0.1-0.2\%.

Mitchell et al. (2011) Role of mother's genes and environment in postpartum depression. Proceedings of the National Academy of Sciences, 108(20), 8189-8193. The prevalence of depression in Iran reaches $14-21.4 \%$ and about $1.89 \%$ depression occurs in women every year and three times that experienced by women in the first five months after giving birth.

De Jager et al. (2010) also found that postpartum depression that is not treated properly has been shown to inhibit breastfeeding continuity. Kruckman (2011) explained that the causes of postpartum depression are biological factors due to the hormones estrogen, progesterone and prolactin, a history of labor complications, education related to social pressure, and role conflicts, duration of labor and medical intervention during labor, parity, and social support factors.

The information, experiences and problems obtained by mothers with a history of postpartum depression vary, such as; Mother traumatized by medical intervention, experiencing prolonged labor, narrow pelvis, lack of husband/family support and various other complications of pregnancy and childbirth. This happens because of the lack of maternal coping mechanisms for the psychological adaptation of the mother during the postpartum period so that the mother has the potential to experience postpartum depression.

The results of the discussion from in-depth interviews (independent interviews) that have been carried out are: As stated by the "first" informant, in this case the mother with a history of postpartum depression with the initials Mrs "A" 37 Years "When the mother is about to give birth the mother is always recommended to the hospital on the grounds that if the mother in labor always experiences prolonged labor because the size of the mother's pelvis is not normal and mothers also sometimes give birth to macrosomic babies/big babies so that the mother's labor process takes a long time.

So the mother must be helped in services that have complete facilities. And the mother also said that related to the long parturition experienced by the mother, she always thought about it and became a burden alone until she had difficulty sleeping and decreased appetite because she was thinking too much so that the birth complications made the mother post-partum depression. And long before the mother became pregnant, the mother had a history of depression, when various problems of childbirth complications faced by depressed mothers appear again after post partum mothers. (Mrs. A, 37 Years old)

This is as explained by (Sarwono 2005), the length of labor is marked by the time it takes for a mother to be able to complete labor starting from the opening of the cervix to the release of the products of conception (fetus and uri) amniotic fluid and placenta. The duration of labor in 
a mother is not easy to determine precisely because the onset of labor is sometimes unclear and subjective.

prolonged labor is labor that lasts more than 24 hours in primiparas and more than 18 hours in multiparas, the causes of prolonged labor are the size and shape of the mother's pelvis and the size of the fetus in the uterus as experienced by this informant having a large baby's narrow pelvis thus causing prolonged labor.

The size of the fetus in the uterus also causes prolonged labor because the baby will adjust to the mother's pelvic bone, in conditions of long labor handling with the above causes, it can cause depression in the mother due to the risk of complications that can arise due to the long handling process (more than 24 hours in pregnancy). primiparas and more than 18 hours in multiparas).

In conditions of long labor handling will make the level of postpartum depression of the mother worse. Judging from this theory, the presence of labor complications that cause prolonged labor can make the postpartum mother's depression level increase so that the mother will experience postpartum depression. This is in line with the research of Sumira (2013) that there is an influence of His, pelvic size and maternal age with the length of labor.

Sari (2020) In a previous history of depression or other emotional problems, those with a history of depression before pregnancy have a higher risk of developing postpartum depression. Bloch (2009) identified risk factors that cause mood disorders in postpartum mothers, namely the presence of mood disorders in the third trimester, previous history of depression, history of major depression or other psychiatric disorders and family history of depression in childhood or adolescence can also be a factors that play a role in the incidence of postpartum depression.

Information obtained from the "second" informant explained that after the mother gave birth, the mother suddenly felt moody, sometimes sad, sometimes happy, her appetite decreased and it was difficult to concentrate, irritable and tired, and the mother also said there was a history of certain diseases such as DM, asthma and During pregnancy, sometimes the mother's blood pressure increases or the mother has hypertension. So with this problem the mother's delivery must also be assisted with action (Sectio caesare /SC). And the mother's level of anxiety is also quite high, always thinking about negative things from bad events that happen to someone during pregnancy, and the mother always thinks she is afraid of it happening to her. This is what makes the burden on the mother's mind increase because the mother is traumatized by medical intervention because the mother has a history of hypertension to experience preeclampsia and eclampsia. The trauma experienced by the mother after undergoing the delivery process is the main cause of postpartum depression that she has ever experienced (Mrs. R'Age 42 years).

The trauma experienced by the mother after undergoing the delivery process makes the mother post-partum depression. a moody and suddenly sad and happy state that the mother feels because of hormonal changes because basically during pregnancy, levels of estrogen (estradiol, estriol and estrone) and progesterone increase as a result of the placenta producing these hormones, as a result of the birth of the placenta during childbirth, estrogen levels and progesterone decreased sharply, reaching pre-pregnancy levels on the fifth day, levels of betaendorphin, human chorionic gonadotropin (HCG) and cortisol which increased during pregnancy and reached maximum levels near aterm also decreased during delivery.

High estrogen levels during pregnancy stimulate the production of thyroid hormone binding globulin, increasing T3 (triiodothyronine) and T4 (thyroxime), so that free T3 and T4 levels decrease. As a consequence, thyroid stimulating hormone (TSH) increases to compensate for 
low levels of free thyroid hormone., so that the levels of free T3 and T4 remain normal. With decreasing levels of thyroid hormone binding globulin after delivery, total levels of T3 and T4 decrease, while free T3 and T4 are relatively constant (Yim et al, 2009' Bloch et al, 2006).

Estradiol and estriol are the active forms of estrogen formed by the placenta, and bind during pregnancy 100 out of 1000 times. Due to the synthesis of ektradiol derived from the metabolic activity of the fetus, the concentration during pregnancy is very high. Based on animal experiments, strengthening the function of neurotransmitters by increasing the synthesis and reducing the breakdown of serotonin, so theoretically the decrease in estradiol levels due to childbirth plays a role in causing postpartum depression.

Prolactin levels rise during pregnancy, peaking at delivery, and in women who do not breastfeed return to their pre-pregnancy state within three weeks of delivery. With the release of oxytocin, a hormone that stimulates lactotropic cells in the anterior pituitary, breastfeeding keeps prolactin levels high. However, even breastfeeding women will return to normal as before pregnancy. The hormone prolactin is thought to have a role in the occurrence of feelings of anxiety, depression. And sometimes postpartum mothers will feel a mood disorder and will continue to become postpartum depression if the mother is not able to adjust the psychological adaptations faced during the postpartum period.

Mother said that she had a history of childbirth complications such as having high blood pressure, causing preeclampsia, and every delivery must be carried out by Sectio Caesarea, this is as Prawirohardjo (2008) said Mothers who have a history of complications or medical history (health) that the mother has greatly affects the fetus during pregnancy, the diseases experienced by the mother during pregnancy greatly affect the development of the fetus during pregnancy and childbirth. This disease has the potential to cause abnormal fetal growth, premature, LBW (Low Birth Weight), and even death. With a history like this, depression in the mother can occur during pregnancy because the mother has a risk that can be fatal to herself and her fetus (infant).

The surgical process that has been experienced will affect the next delivery process, mothers who have had a Caesarean will be at risk of uterine rupture (tears in the uterine wall) This risk makes depression during pregnancy can become more severe when entering labor and after delivery due to tearing of the uterine wall can threaten the safety of both mother and baby. so that things like this will exacerbate the level of maternal depression.

Information obtained from the informant "third" with the initials Mrs. S" Age 46 years with a junior high school background with an IRT job explained that the complaints of side effects felt by the mother in using contraceptives made the mother not want to be a family planning acceptor. And also not getting support from the husband so that the distance between the births of children and mothers is not maintained and the mother's parity is quite high. That is parity 7 This is in accordance with the statement of Manuaba (2008) factors that influence parity, one of which is education and cultural background, Education, the higher a person's education level, the easier it is to obtain information, so that the mother's ability to think more rationally, have higher education will think more rationally that the ideal number of children is 2 people.

Cultural background, universal culture are cultural elements that are universal, exist in all cultures in the world, such as knowledge of language and basic repertoire, ways of social interaction, customs, general judgments without being based on culture have instilled a line of influence on attitudes towards various cultures. problem.

With the father's statement that he did not allow the mother to do family planning because there are still cultural assumptions that are believed to be "many children, lots of luck" without considering the risks experienced by multiparous mothers in the delivery process. 
Culture has colored the attitudes of community members because it is culture that gives the experience of individuals who are members of the community they care for. Only the belief of individuals who know and understand about the ideal number of children, then the mother will behave according to what she knows (Friedman et al., 2005).

Parity is the number of children born to the mother, up to parity 3, the mother's uterus can return to the way it was before pregnancy, every pregnancy the uterus enlarges, the uterine muscles stretch during the 9 months of pregnancy. As a result of this stretch, the elasticity of the uterine muscles does not return to what it was before pregnancy after delivery, the more often pregnant women give birth, the closer the distance between pregnancy and birth, the more disturbed the elasticity of the uterus, as a result the uterus does not contract perfectly and results in post-pregnancy bleeding (Sarwono, 2005).

The risk of post-pregnancy bleeding and birth that the mother thinks is the risk of postpartum depression. This is because bleeding can lead to fatal conditions to the death of the baby and/or the death of the mother. This factor is the primary cause of the emergence of postpartum depression regarding the number of children or maternal parity, Soep (2009), found that there was a relationship between maternal parity and postpartum depression.

Information obtained from the "fourth" informant with the initials Mrs. 'K' aged 39 years explained that the mother felt that she did not get the husband's support even though her husband's support was the main factor in the integrity of a household relationship.

Support can be described as a feeling of belonging that someone is an active participant in daily activities (Hadok, 2008), support is a motivation or encouragement and also actions taken to be able to interact with others in order to make changes to better behavior to meet needs.

Of all sources of social support, social support from the husband is the first and foremost support in providing support to the wife. This is because the husband is the first person to be aware of a change in his partner, if he judges that his husband provides support for him, it will be able to allow a positive influence on the prospective mother.

In this case, the husband's lack of support in supporting his wife can cause postpartum depression. The role of husband and wife is very important, especially in taking care of and caring for their baby, if postpartum is a time when the wife is still in a weak condition physically and mentally, she needs a role and love. dear husband, the lack or absence of husband's support will make the wife feel disappointed which will have an impact on the emergence of post partum depression.

Husband's support is very important and cannot be underestimated and last but not least it builds a positive atmosphere, where the wife feels the first days are tiring. Therefore, support or a positive attitude from your partner and family will give you its own strength.

Llewellyn-Jones (2009), said that the characteristics of women who are at risk for postpartum depression are women who have a history of depression, women who come from less harmonious families, women who do not get support from their husbands or those closest to them during pregnancy. and after giving birth. The results of research conducted by Destriyana (2012), family support (husband) is the best way to help mothers who are affected by postpartum depression because the attention of loved ones strengthens them through difficult times after giving birth.

The "fifth" informant with the initials Ny'D'Age 35 years old with a junior high school education background, working status as an IRT Housewife, explained that the presence of childbirth complications requires the mother to choose a method of delivery that can minimize fatal conditions that will occur so that the mother must undergo the delivery process with 
surgical procedures. Sectio surgery because by doing a section it can be considered as being able to ease the labor faced by the mother.

It's just that the mother feels traumatized because every time she gives birth, the procedure must be carried out again and this makes the mother traumatized, because it is related to the method of delivery given to the mother as determined by the doctor or what occurs based on the mother's condition to give birth either normally assisted by a shaman, midwife or obstetrician or performed by caesarean section with each of the risks that can be caused.

For mothers who have experienced cesarean section and are aware of the risks they receive, then for the next delivery it becomes a fear in itself for mothers who are facing the birth of a baby, this is the risk of the emergence of post partum depression in mothers who choose a method of delivery that the mother is afraid to undergo alone.

The information obtained from key informants was that there were mothers who came postpartum and were referred to the RSKD with psychiatric symptoms such as sensitivity, irritability, crying and even tantrums until they could not control themselves and had difficulty concentrating do not recognize themselves and show other symptoms of depression (Sari, 2020).

This is because there are many things and problems and childbirth complications experienced by mothers during the process of pregnancy and childbirth. which may at any time this problem can disrupt the mother's psychological adaptation so that the mother cannot stem the coping mechanisms of the problems faced so that postpartum depression can arise for mothers who have given birth.

By acting as a new mother, a woman can feel her life becomes more meaningful and meaningful. This can increase self-confidence in playing a role in everyday life, both in the family (as a wife and as a mother), as well as in the community (in the neighborhood, at work, or in the social environment, in enjoying the days with babies who eagerly awaited, the new mother will feel different feelings, which may not even have been imagined before.

In general, new mothers will be amazed and stunned to see and feel how beautiful and cute their babies are, how fun it is to play and see and hear their chatter. The new mother will also be excited to breastfeed her baby, she will hardly feel tired because she feels that she is meaningful to her baby, thus she will feel that her life is more meaningful.

However, this is not the case with a small number of women who actually feel sad, irritated, tired, just want to be angry, feel insignificant, and hopeless, in living the days after giving birth to the son or daughter they had been waiting for. These feelings will be followed by a reluctance to take care of the baby, lazy to breastfeed, have thoughts of suicide or even want to kill the baby. If this is allowed to continue for a long time and is not addressed immediately, it will certainly be bad for the mother, for the baby who does not know anything, also for the personality development of the baby, and for the relationship between the mother and the baby. The condition of a mother like that will also affect the husband and wife relationship in a broad sense, including in communication, giving attention, tolerance and in sexual relations, which over time can also affect the integrity of their family. postpartum depression.

Determinants of the causes of postpartum depression are influenced by several factors apart from complicating factors in pregnancy and childbirth are also influenced by individual social support factors and many other factors. Considering that the impact of postpartum depression is not only on the mother but also on the child itself and other family functioning systems, it can be disrupted so that postpartum depression must get the right treatment. 
The information obtained from supporting informants in this case is the husband/family of the mother with a history of postpartum depression, namely the family/husband feels uncomfortable and feels sorry for the mother who is depressed because the mother is not able to take care of her baby properly and cannot have a good relationship with both the family and the child remember the condition of the mother who is depressed, and the husband also feels sorry and concerned because sometimes the role and function of the mother is replaced by the father or even from the family where these roles and functions are supposed to be carried out by the mother, but because of the mother's condition, which is not allows.

The husband or family and even the mother herself should have to know the causes of postpartum depression that might occur so that at the beginning it can prepare mentally and coping mechanisms for the mother to avoid things that can cause postpartum depression, so that this postpartum depression can prevent early.

From the problems experienced by the informants, the average informant complains subjectively which can be seen from the complications of childbirth and the social support faced by the mother, where the problems they experience have a physical impact on postpartum mothers such as difficulty eating, sleep disturbances, sensitivity, sometimes sad, sometimes angry, can't control themselves, have difficulty concentrating and show other symptoms of depression, so that it affects mood disorders. And the effect on the psychological adaptation of the mother, causing postpartum depression to the mother. And the mother also feels stressed at the beginning of pregnancy, it's just that the mother's stress level is still in a mild stage because the various problem conditions experienced will worsen the postpartum depression level of the mother. So in these conditions that cause postpartum depression in the mother.

\section{Conclusion}

Based on the discussion of the results of the study regarding the Analysis of Post Partum Depression in Mothers with a History of Post Partum Depression at a special hospital in the province of South Sulawesi. Mothers who have experienced postpartum depression are mothers aged 31-40 years. By complaining about problems subjectively where mothers complain of various problems faced during pregnancy and childbirth, the following conclusions can be drawn; (1) In conditions of prolonged labor experienced by the mother due to various labor complications encountered, will cause long treatment, in conditions of long labor handling it can cause depression in the mother due to the risk of complications that can arise due to a long treatment process of more than 24 hours in primiparas and more than 18 hours in multiparas, so that this prolonged treatment condition will make the mother's level of depression worse. With a history of depression before pregnancy, it has the potential to reappear if there are factors that make the mother stressed, such as in the birth process experienced by the mother. And will get worse in postpartum; (2) Lack of husband support in supporting his wife can cause postpartum depression, the role of husband and wife is very important, especially in taking care of and caring for their baby, if postpartum is a time when the wife is still physically weak, and mentally needs the role of love husband, lack or absence of husband's support will make the wife feel disappointed which will have an impact on the emergence of postpartum depression; (3) Parity is the number of children born to the mother, the more often the mother gives birth, the closer the distance between pregnancy and birth, the elasticity of the uterine muscles will be increasingly disturbed, as a result the uterus does not contract perfectly and results in postpregnancy bleeding. post partum. And delivery is an action given by the mother that is determined by the doctor or which occurs based on the mother's condition. The history of illness and complications experienced by the mother greatly affect the fetus during pregnancy. If there is a history like this, maternal depression will appear. 


\section{Suggestion}

Communicate all problems or other things that you want to express, talk about the anxiety you are experiencing, be sincere in accepting new activities and roles after giving birth, be flexible and not too perfectionist in taking care of the baby and household. Learn to calm down and take deep breaths and meditation, need adequate rest, sleep when the baby is sleeping, do light exercise, join a group of mothers, consult a doctor or professional person in order to minimize other risk factors and carry out supervision. Mental support from the surrounding environment, mental support is needed, this support is not only from husband, but can be from family, friends and the surrounding environment. If you want to share your emotional feelings and life changes with someone who you believe can be a good listener, post partum mothers must have confidence that the environment will support them and are always ready to help if they experience difficulties. Post partum mothers should express what they feel, don't keep your feelings to yourself, if you have a problem, you should immediately discuss it with your husband and the closest people so that you can be more comfortable.

\section{References}

Anindyajati, G., Ismail, R. I., Diatri, H., \& Elvira, S. D. (2017). Antenatal depression and its determinant factors in urban community setting. Advanced Science Letters, 23(4), 3439-3441.

Banerjee, P., Joy, K. P., \& Chaube, R. (2017). Structural and functional diversity of nonapeptide hormones from an evolutionary perspective: a review. General and Comparative Endocrinology, 241, 4-23.

Bloch, M., Rotenberg, N., Koren, D., \& Klein, E. (2006). Risk factors for early postpartum depressive symptoms. General hospital psychiatry, 28(1), 3-8.

Chaplin, C.P. (2001).Kamus Lengkap Psikologi .Yogyakarta: Liberty

De Jager, E., Broadbent, J., Fuller-Tyszkiewicz, M., \& Skouteris, H. (2014). The role of psychosocial factors in exclusive breastfeeding to six months postpartum. Midwifery, 30(6), 657-666.

Friedman, S. H., Horwitz, S. M., \& Resnick, P. J. (2005). Child murder by mothers: a critical analysis of the current state of knowledge and a research agenda. American Journal of Psychiatry, 162(9), 1578-1587.

Hadok, J. (2008). Performing Arts Healthcare in Australia-A Personal View. Medical Problems of Performing Artists, 23(2), 82-84.

Hairiyah, H. (2011). Efektivitas Pelatihan Kecakapan Hidup Terhadap Kepercayaan Diri Berwirausaha Penyandang Cacat Fisik(Doctoral dissertation, Universitas Muhammadiyah Surakarta).

Kruckman, (2001). Depresi pasca salin. Buku ajar keperawatan maternitas. Jakarta: ECG

Llewellyn-Jones, D. (1958). The prevention of maternal death. Central African Journal of Medicine, 4(8), 340-344.

Manuaba I. B. G. (2007).Obstetri Gynekology. Buku Kedokteran: ECG

Mitchell, C., Notterman, D., Brooks-Gunn, J., Hobcraft, J., Garfinkel, I., Jaeger, K., ... \& McLanahan, S. (2011). Role of mother's genes and environment in postpartum depression. Proceedings of the National Academy of Sciences, 108(20), 8189-8193. 
Notoatmodjo, S. (2012). Promosi kesehatan dan perilaku kesehatan. r2kn.litbang.kemkes.go.id

Nursalam, N., Elina, Y., \& Wahyuni, E. D. (2010). The analysis of job satisfaction nurse based on organizational climate. Jurnal Ners, 5(2), 154-163.

Riani, I., Dahrianis, D., \& Nur, M. (2013). Faktor yang Berhubungan dengan Tingkat Depresi pada Pasien Post Partum Di Rsia Siti Fatimah Makassar. Jurnal Ilmiah Kesehatan Diagnosis, 1(6), 81-88.

Rukmini , (2003). Promosi Kesehatan \& Pendidikan Kesehatan. Jakarta. ECG

Sari, R. A. (2020). Literature Review: Depresi Postpartum. Jurnal Kesehatan, 11(1), 167-174.

Sarwono. P. (2010). Ilmu kebidanan. Jakarta: PT Bina Pustaka

Soep, (2009). Pengaruhi Intervensi Pseudoedukasi Dalam mengatasi Depresi Post Partum di RSU DR. Pimgadi Medam

Sumira, N., Nirwana, N., \& Mato, R. (2013). Faktor Faktor Yang Mempengaruhi Lamanya Persalinan Pada Ibu Multipara Di Rsia St. Fatimah Makassar.

Yim, I. S., Glynn, L. M., Schetter, C. D., Hobel, C. J., Chicz-DeMet, A., \& Sandman, C. A. (2009). Risk of postpartum depressive symptoms with elevated corticotropinreleasing hormone in human pregnancy. Archives of general psychiatry, 66(2), 162169. 